\title{
Stem Cell Therapy: Recent Success and Continuing Progress in Treating Diabetes
}

\author{
Elton Mathias $^{1 *}$, Roveena Goveas ${ }^{2}$ and Manish Rajak ${ }^{1}$ \\ ${ }^{1}$ Innvocept Solutions, Mumbai, India \\ ${ }^{2}$ Department of Internal Medicine, Mountainside Medical Center, Montclair, USA
}

*Corresponding author: Elton Mathias, Medical Professional, Innvocept Solutions, Mumbai, India, Tel: +1-(732)-8045257, E-mail: elton.mathias@innvoceptsolutions.org

\begin{abstract}
Diabetes mellitus (DM), a cluster of metabolic diseases, resulting in high blood glucose levels, is prevalent in today's world. The global costs of diabetes and its consequences are rising and are expected substantially increase by 2030 , especially in middle- and lower-income countries. Evidence-based therapies, specifically targeting the reduction of high blood glucose levels, and minimizing diabetic complications, are currently the choice of treatment. Stem cell therapy offers a promising vision to treat DM. Although challenges are still posed with this line of therapy, studies have produced regenerative beta-cells which closely resemble insulin-secreting cells. A number of sources for stem cells have been explored, ever since the proof-of-concept for cell therapy was laid down. This review summarizes stem cell therapy in the treatment of DM.
\end{abstract}

\section{Keywords}

Stem cells, Diabetes, Islets, Pancreas

\section{Introduction}

According to the WHO report released in November 2017 the number of people with Diabetes mellitus (DM) has risen from 108 million in 1980 to 422 million in 2014 [1]. The prevalence of DM across all age-groups, worldwide was estimated to be $2.8 \%$ in 2000 and is expected to rise to $4.4 \%$ by 2030 , with the total number of people with DM projected to rise from 171 million in 2000, to 636 million in 2030 [2].

There are two types of DM - type 1 and type 2. Type 1 diabetes, also known as insulin-dependent diabetes and juvenile diabetes, involves the immune system, which results from a cellular-mediated autoimmune destruction of the BETA-cells of the pancreas. It can occur at any age, but most often occurs in children and young adults. The etiology of DM type 1 is not fully uncovered, however in most cases, the body's immune system attacks and destroys insulin producing beta-cells. Family history is known to play a role, in about $10 \%$ to $15 \%$ of people with DM type 1 . Type 2 diabetes, also known as adult-onset DM, which usually develops after the age of 40 but can appear earlier in obese patients. With DM type 2, the pancreas produces insulin, but the body cannot use it effectively. Insulin treatment is not always necessary, in these patients, as with DM type 1. Diabetes mellitus is associated with severe long-term microand macrovascular complications and carries a high rate of morbidity and mortality. Both DM type 1 and 2 are a significant public health concern with numerous debilitating complications. The global costs of diabetes and its consequences are rising and are expected substantially increase by 2030 [1], especially in middleand lower-income countries. Evidence-based therapies, specifically targeting the reduction of high blood glucose levels, and minimizing diabetic complications, are currently the choice of treatment [3].

The pathogenesis of DM, whether type 1 or type 2 , can be traced back to the dysfunction of the pancreatic beta-cells. Although approved therapies that enhance beta-cell function exist, there are none that lead to the regeneration of the lost or dysfunctional beta-cell [4]. Studies have shown that beta-cells can be reprogrammed, with certain molecules, such as GABA [5] and hormone [6]. However, these studies also bring to light a lot of uncertainties that need to be explored [4]. Stem cells for the treatment of DM come from a variety

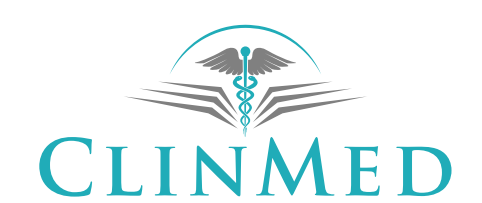

INTERNATIONAL LIBRARY
Citation: Mathias E, Goveas R, Rajak M (2018) Stem Cell Therapy: Recent Success and Continuing Progress in Treating Diabetes. Int J Stem Cell Res Ther 5:053. doi.org/10.23937/2469-570X/1410053 Accepted: June 26, 2018: Published: June 28, 2018

Copyright: (c) 2018 Mathias E, et al. This is an open-access article distributed under the terms of the Creative Commons Attribution License, which permits unrestricted use, distribution, and reproduction in any medium, provided the original author and source are credited. 


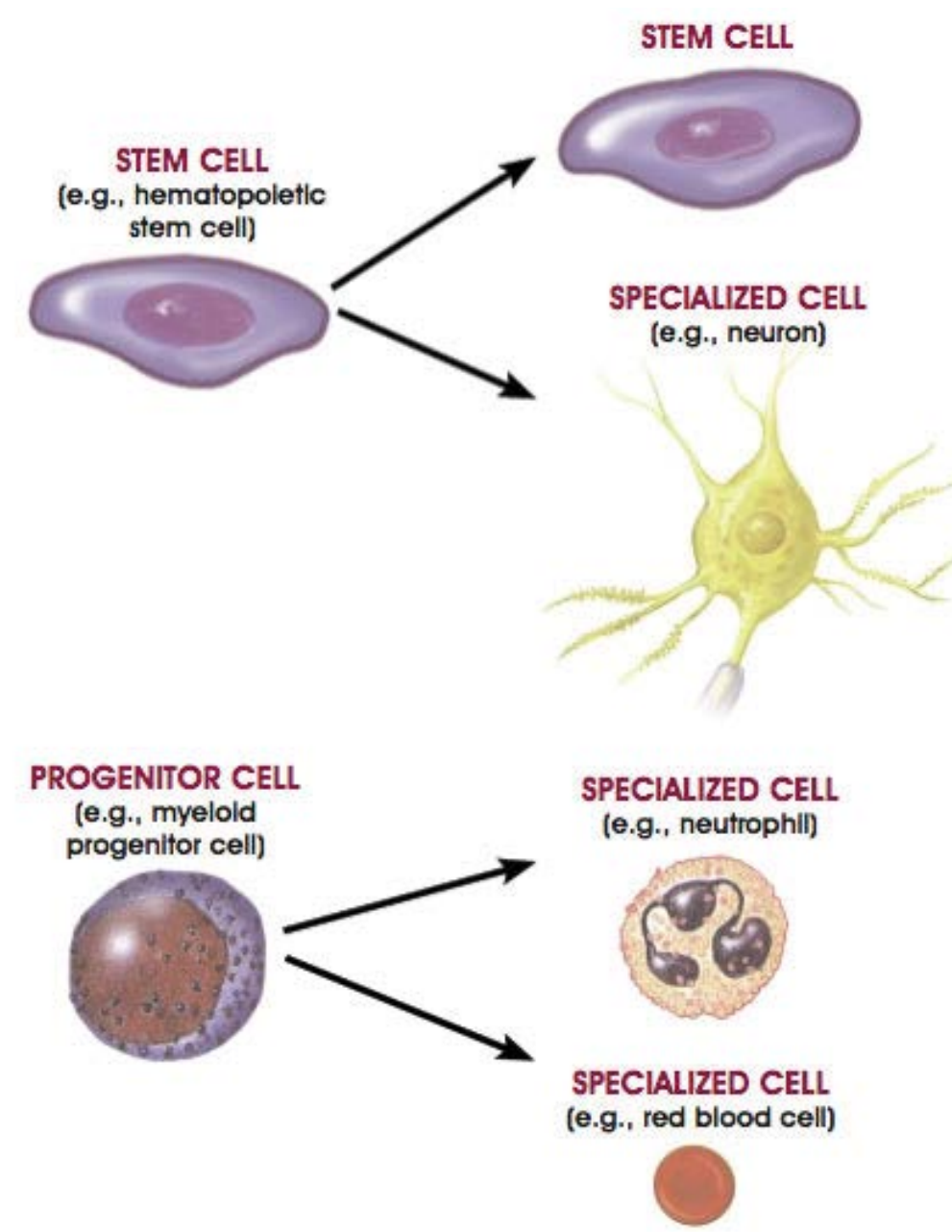

Figure 1: Formation of differentiated cells and specialized cells from stem cells and progenitor cells.

of biological sources like embryos, placenta, and bone marrow. Progenitor cells are another exciting avenue of research. Like stem cells, these cells can take on the form of a number of different types of mature human cells, however, unlike stem cells, they cannot divide indefinitely.

Progenitor stem cells have been used to grow insulin producing cells, under laboratory conditions, from intestinal cells and undeveloped pancreatic cells [7]. This article provides an overview of the various approaches used to regenerate pancreas in patients with diabetes, recent advances including our contributions and also a novel approach that may be explored in future.

Progenitor cell are very similar to stem cells. They are biological cells and like stem cells, they too have the ability to differentiate into a specific type of cell. However, they are already more specific than stem cells and can only be pushed to differentiate into its "target" cell. Whereas, stem cells have the ability to differentiate into many different types of cells as shown in Figure 1. Comparison between Stem Cell and Progenitor Cell are highlighted in detail in Table 1.

\section{Islet Cell Transplants}

Pancreatic islets include the insulin producing beta cells, which are crucial in regulating blood glucose levels.
Islet transplants are a safer option than whole pancreas transplants. The procedure to insert donor islet cells is far less critical than transplanting a complete pancreas. For any type of transplantation procedure, a balance is sought between efficacy and toxicity. With respect to islet transplantation a main concern was that many of the current agents' cause damage beta cells or induce peripheral insulin resistance [8,9]. Immunosuppressant drugs also can cause problems, as suppressing the immune system raises the risk of infection [10].

Shapiro, et al., reported insulin independence, with tight glycemic control and correction of glycated hemoglobin levels, in seven consecutive subjects treated with glucocorticoid-free immunosuppressive therapy combined with infusion of an adequate mass of freshly prepared islets from two or more pancreases from deceased donors [11]. This treatment came to be known as the Edmonton Protocol [12]. In continuation to this protocol, a phase I/II clinical trial was undertaken to demonstrate the feasibility and reproducibility of the outcomes of the Edmonton protocol. The trial concluded that though long-term endogenous insulin production and glycemic stability in subjects with type 1 diabetes mellitus was achieved, it was found that insulin independence was more than often not sustainable, and gradually lost in the long run [13]. 
Table 1: Comparison between Stem Cell and Progenitor Cell.

\section{Comparison in Stem Cell}

\section{Progenitor Cell}

Description Stem Cells are reserve cells that have the ability to change Progenitor cell are very similar to stem cells. They into many different types of cells and grow indefinitely. They are biological cells and like stem cells, they too have have the potential to create many new different cells that can the ability to differentiate into a specific type of cell. help replace dying and/or damaged cells. Stem cells also However, they are already more specific than stem have the potential to create new tissue and even whole or-cells and can only be pushed to differentiate into its gans from just a few stem cells.

Types $\quad$ Four main types of stem cells: "target" cell.

1. Adult or somatic stem cells

Many, as each "target" cell has its own progenitor

2. Fetal stem cells

3. Embryonic stem cells

4. Induced stem cells cell. Some of the types include:

1. Satellite cells found in muscles.

2. Intermediate progenitor cells formed in the subventricular zone.

3. Bone marrow stromal cells

4. Periosteum contains progenitor cells that develop into osteoblasts and chondroblasts.

5. Pancreatic progenitor cells

6. Angioblasts or endothelial progenitor cells (EPC)

7. Blast cells

Features $\quad 1$. Multiply by cell division to replenish dying cells and regen- 1 erate damaged tissues.

2. Generate all the cell types of the organ from which they originate.

Tendency to differentiate into a specific type of cell, but is already more specific than a stem cell and is pushed to differentiate into its "target" cell.

3. Potentially regenerating the entire organ from a few cells

2. Can divide only a limited number of times.

Benefits $\quad$ They have the potential to increase healing and for potentially They act as a repair system for the body. They reregenerating an entire organ from a few cells. They are inves- plenish special cells, but also maintain the blood, tigated in treatment of:

1. Diabetes skin and intestinal tissues. Progenitor cells can

2. Rheumatoid arthritis be activated in case of tissue injury, damaged or

3. Parkinson's disease

4. Alzheimer's disease

5. Osteoarthritis

6. Stroke and traumatic brain injury repair

7. Learning defects

8. Spinal cord injury repair

9. Heart infarction

10. Anti-cancer

11. Baldness

12. Replace missing teeth

13. Repair hearing

14. Restore vision

15. Amyotrophic lateral sclerosis

16. Crohn's disease

17. Wound healing

Controversy The use of human adult stem cells in research and therapy The progenitor cells are not subject to controveris not considered to be controversial. The use of human em- sy. bryonic stem cells in research and therapy is controversial as they are derived from human 5-day-old embryos generated by IVF (in vitro fertility) clinics designated for scientific research.

Future studies/trials should focus on enhanced islet engraftment, less toxic immunosuppressive therapy, reduced metabolic stress, reduced apoptosis, enhanced regeneration, the use of living donors, and the induction of immunologic tolerance. This approach will ensure improved success rates in transplantation and sustained insulin independence [13]. In 2017, Westenfelder, et al., [14] reiterated the need for re-establishing endogenous insulin secretion without being limited by both the scar- city of organ donors and the life-long need for often-toxic antirejection drugs. He and his team argued that intrahepatic islet transplants were inefficient, due to the high number of donors required per treatment and was also associated with high early losses of islets [15]. They hypothesized that high numbers of mesenchymal stem cells (MSCs) in neo-islets (NIs) would enable islet cells to survive and re-differentiate into normally functioning endocrine cells. 
This treatment led to long-term glycemic control in non-obese diabetic mice [14]. The NIs survived, engrafted and re-differentiated into functional insulin secreting cells in the well-vascularized omentum (via intraperitoneal administration), delivering insulin into the hepatic portal system. Simultaneously, re-expression of other islet-specific hormones occurred. Identical injection of Nis into nondiabetic animals resulted in omental engraftment without causing hypoglycemia, further demonstrating regulated islet hormone secretion [14]. Both allo- and auto-immune protection was also achieved $[16,17]$. In preparation for a pilot study in pet dogs with DM type 1, streptozotocin-diabetic nonobese diabetic/ severe combined immunodeficiency (NOD/SCID) mice were treated in a similar manner with canine NIs (cNIs). In these, euglycemia was readily and durably induced and intraperitoneal Glucose Tolerance Tests (i.p. GTTs) were normalized by the exclusive release of canine-specific insulin [14].

Ongoing studies regarding this $\mathrm{NI}$ technology are focused on analogous studies using human NIs in diabetic NOD/SCID mice, as well as on the characterization of the NI-intrinsic microcirculation post-engraftment in the omentum, the long-term distribution of MSCs within the NIs in vivo, their potential differentiation into insulin-producing and vascular endothelial cells, the re-differentiation of alpha and other endocrine cells in vivo, in situ IDO (canine) and iNOS (murine) expression by MSCs, and a detailed analysis of the long-term histology and cell composition of functioning NIs [14]. In patients with DM type 1, glycemic control can also be achieved with intensive insulin therapy and pancreatic transplantation. Intensive insulin therapy does not normalize glycosylated hemoglobin values and may cause severe hypoglycemia. Pancreatic transplantation provides excellent glycemic control, and although the outcome of the procedure has improved dramatically over the past decade, it remains an invasive procedure with a substantial risk of morbidity. The findings indicated that islet transplantation alone is associated with a minimal risk and results in good metabolic control, with normalization of glycosylated hemoglobin values and sustained freedom from the need for exogenous insulin $[18,19]$.

Hematopoietic and Bone Marrow Cells for Type 2 Diabetes Mellitus (DM TYPE 2)

Autologous bone marrow contains hematopoietic stem cells, a mixture of mononuclear cells, a few mesenchymal cells, and other cells. Peripheral blood stem cells are mainly selected by their CD34 antigen positivity. Different preparations of the hematopoietic cells have been claimed to be effective in correcting hyperglycaemia, improvement of endogenous insulin production, and diminishing or eliminating the need for insulin and other diabetes controlling treatments [1921]. Wang, et al., [22] used autologous bone marrow to treat 31 patients with stem cell infusion into the major arteries feeding the pancreas. The HbA1c dropped by $>$ $1.5 \%$ within 30 days and the C-peptide increased at the 3-month follow-up mark. All patients were reported to have had a significant reduction of their anti-diabetic medications [23].

Bone marrow-Mononuclear Cells (BM-MNC) were used by Bhansali, et al., [19] in a prospective, randomised, placebo-controlled trial designed to treat 11 patients. Nine of the 11 patients (82\%) achieved $50 \%$ reduction of the insulin requirements and 10 (91\%) achieved a $\mathrm{HbA} 1 \mathrm{c}<7 \%$ in the intervention group.

These two recent meta-analysis of published trials concluded that both BM-MNC and peripheral blood mononuclear cell infusion may result in improvement of the HbA1C, fasting plasma glucose, C-peptide levels, and endogenous insulin production at 12 months in the majority of treated patients.

\section{Human Embryonic Stem Cells}

Embryonic Stem cells can differentiate in vitro and in vivo, to form a wide range of specialized cell types. Taken from the embryo at the blastocyst stage, ES cells are pluripotent. Their versatility is an asset over adult stem cells, but also a challenge. While ES cells can become insulin-secreting cells in culture, e.g., the cells are not as stable as adult stem cells. ES cells studied in vitro and in vivo can differentiate into tumor cells. Similarly, the rapid proliferation rate of ES cells, which is also greater than that of adult cells, carries greater risk of forming tumors in vivo [24-26]. The discovery of methods to isolate and grow human-Embryonic Stem Cells (ESCs) in 1998 renewed the hopes of researchers, clinicians and diabetes patients and their families that a cure for DM TYPE 1 and perhaps non-DM TYPE 1 as well may be within striking distance. In theory, ESC could be cultivated and coaxed into developing the insulin-producing islet cells of the pancreas. With a ready supply of cultured stem cells at hand, the theory is that a line of ESC could be grown up as needed, for anyone requiring a transplant.

\section{Stem Cell Research - Advantages and Disadvan- tages}

The list of sources of stem cells advantages and disadvantages are cited in the Table 2.

\section{Advantages}

1) It provides medical benefits in the fields of therapeutic cloning and regenerative medicine.

2) It provides great potential for discovering treatments and cures to a variety of diseases including Parkinson's disease, schizophrenia, Alzheimer's disease, cancer, spinal cord injuries, diabetes and many more.

3) Limbs and organs could be grown in a lab from stem cells and then used in transplants or to help treat illnesses. 
Table 2: List of sources of stem cells. Their advantages and disadvantages.

\begin{tabular}{|l|l|l|l|}
\hline Stem cell type & Sources & Advantages & Disadvantages \\
\hline Embryonic & Cells from human blastocysts & Pluripotent & Requires embryo destruction \\
\hline Fetal stem cells & $\begin{array}{l}\text { Cells from gonads of aborted } \\
\text { fetuses }\end{array}$ & Multipotent & $\begin{array}{l}\text { Requires destruction of weeks } \\
\text { old fetus }\end{array}$ \\
\hline Umbilical cord stem cells & $\begin{array}{l}\text { Cells from the umbilical cord blood } \\
\text { of newborns }\end{array}$ & Multipotent/Pluripotent? & Low frequency of stem cells \\
\hline Placenta-derived stem cells & $\begin{array}{l}\text { Cells from the placenta of } \\
\text { newborns }\end{array}$ & Multipotent/Pluripotent? & $\begin{array}{l}\text { Low frequency (but higher than } \\
\text { cord blood) }\end{array}$ \\
\hline $\begin{array}{l}\text { Adult stem cells } \\
\text { Induced pluripotent stem (iPS) } \\
\text { cells }\end{array}$ & $\begin{array}{l}\text { Cells from adult tissues } \\
\text { reprogramed to pluripotency }\end{array}$ & Multipotent & Very low frequency \\
\hline
\end{tabular}

The stem cells are the promising tools addressing generation of beta-like cells/ISC (Insulin secreting cells) as well as immunomodulation (Figure 2) [25].

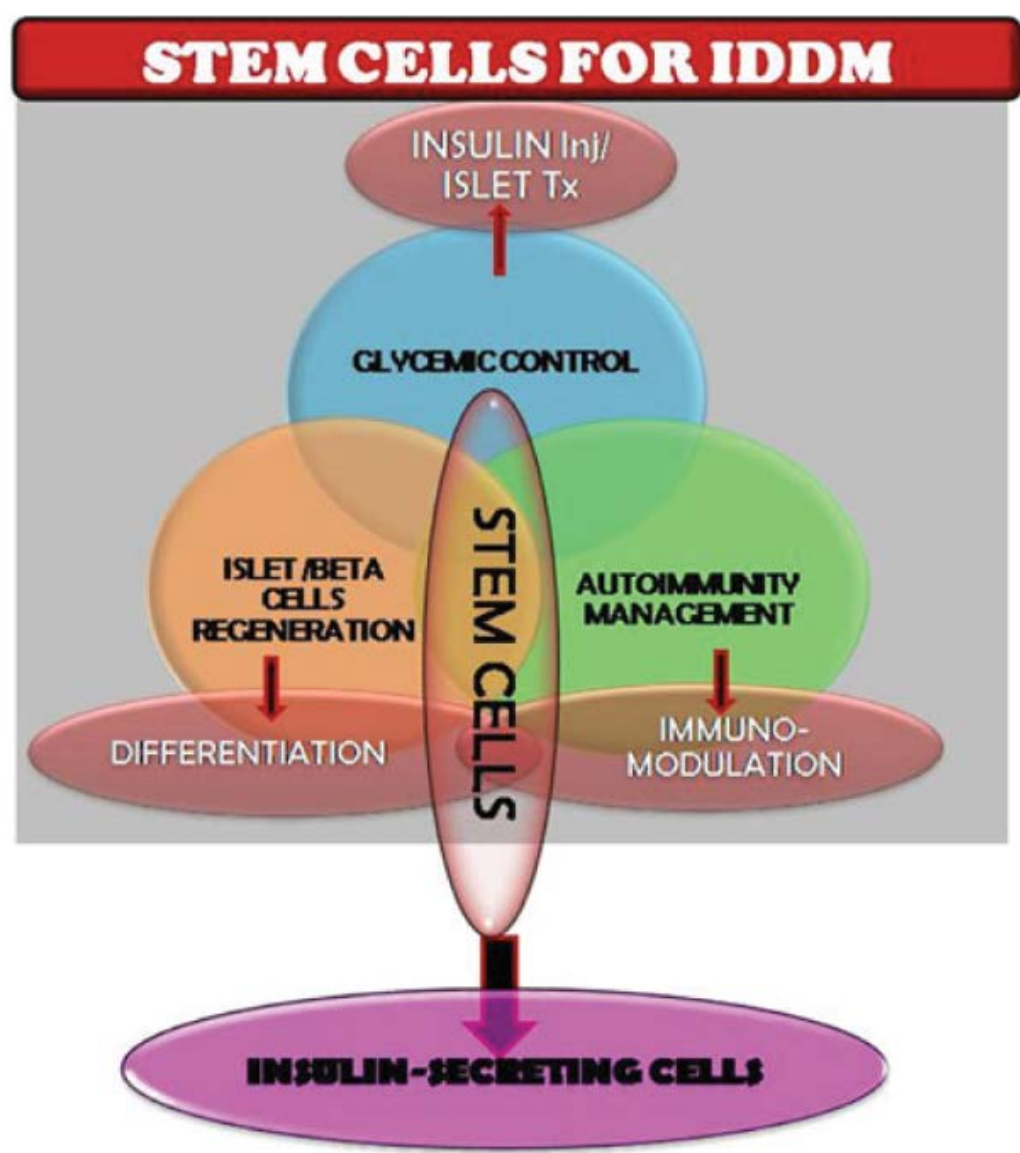

Figure 2: Showing Stem cells for IDDM.

4) It will help scientists to learn about human growth and cell development.

5) Scientists and doctors will be able to test millions of potential drugs and medicine, without the use of animals or human testers. This necessitates a process of simulating the effect the drug has on a specific population of cells. This would tell if the drug is useful or has any problems.

6) Stem cell research also benefits the study of development stages that cannot be studied directly in a human embryo, which sometimes are linked with major clinical consequences such as birth defects, pregnancy-loss and infertility. A more comprehensive understanding of normal development will ultimately allow the prevention or treatment of abnormal human development.
7) Stem cell research also benefits the study of development stages that cannot be studied directly in a human embryo, which sometimes are linked with major clinical consequences such as birth defects, pregnancy-loss and infertility. A more comprehensive understanding of normal development will ultimately allow the prevention or treatment of abnormal human development.

8) An advantage of the usage of adult stem cells to treat disease is that a patient's own cells could be used to treat a patient. Risks would be quite reduced because patients' bodies would not reject their own cells.

9) Embryonic stem cells can develop into any cell types of the body, and may then be more versatile than adult stem cells. 


\section{Disadvantages}

1) The use of embryonic stem cells for research involves the destruction of blastocysts formed from laboratory-fertilized human eggs. For those people who believe that life begins at conception, the blastocyst is a human life and to destroy it is immoral and unacceptable.

2) Like any other new technology, it is also completely unknown what the long-term effects of such an interference with nature could materialize.

3) Embryonic stem cells may not be the solution for all ailments.

4) According to a new research, stem cell therapy was used on heart disease patients. It was found that it can make their coronary arteries narrower.

5) A disadvantage of most adult stem cells is that they are pre-specialized, for instance, blood stem cells make only blood, and brain stem cells make only brain cells.

6) These are derived from embryos that are not a patient's own and the patient's body may reject them.

\section{Pluripotent Stem Cells}

Pluripotent stem cells (PSCs) have the ability to self-renew and differentiate into three germ layers including ectoderm, endoderm and mesoderm, and hence can play an important role in regenerative medicine and cell therapy. PSCs are obtained from the inner cell mass of blastocyst (embryonic stem cells, ES) or from the foetal genital ridge (embryonic germ cells, EG). Human ES cell lines were first reported in 1998 by Prof. Thomson and his group [27] whereas human EG cell lines were reported by Prof. Shamblott in the same year [28].

Technology also exists to derive PSCs from adult somatic cells by reprogramming them to embryonic state using a cocktail of factors (induced pluripotent stem cells, iPS) or by allowing factors present in the oocyte cytoplasm to reprogramme somatic cells (therapeutic cloning). Prof. Yamanaka shared the Nobel Prize for Medicine in 2012 for iPS technology [29] whereas Prof. Mitalipov's group in 2013 [30] was the first to derive human ES cell line by somatic cell nuclear transfer (SCNT). Jiang, et al., [31] observed that $30 \%$ of transplanted mice showed reduction in hyperglycaemia on transplanting insulin positive cells, obtained by differentiating ES cells, for over a period of six months. Thus, proof of concept for use of human ES cells for diabetes was established; however, the process remains highly inefficient. Schulz, et al., [32] developed a scalable system for producing functional progenitors and Bruin, et al., [33] improved the differentiation protocol further which resulted in grafts containing $>80 \%$ endocrine cells and resulted in single hormonal cells expressing either insulin or glucagon or somatostatin in contrast to earlier polyhormonal cells. Kirk, et al., [34] demonstrated that human insulin was secreted by the seventh week after transplantation, of encapsulated pancreatic progenitors and by week 20 enough human insulin was produced to ameliorate alloxan-induced diabetic symptoms.

\section{Mesenchymal Stem Cells}

Mesenchymal stem cells (MSCs) are self-renewing multipotent cells that have the capacity to secrete multiple biologic factors that can restore and repair injured tissues. Preclinical and clinical evidence have substantiated the therapeutic benefit of MSCs in various medical conditions. Currently, MSCs are the most commonly used cell-based therapy in clinical trials because of their regenerative effects, ease of isolation and low immunogenicity. Experimental and clinical studies have provided promising results using MSCs to treat diabetes.

In 2015, investigators from Sweden were the first to evaluate the safety and efficacy of autologous MSC treatment in newly diagnosed DM type 1 . Stem cells were harvested from the iliac crest bone marrow and the median systemic single dose was $2.75 \times 10^{6}$ cells $/ \mathrm{kg}$. They concluded that administration of MSCs did not result in adverse events in any of the ten patients and provided promising C-peptide concentrations at the 1-year follow-up. This phase I trial did not show any functional differences between the control and MSC group in hemoglobin A1c (HbA1c) or insulin dose.

$\mathrm{Hu}$ and coworkers conducted a single-center, double-blind study examining the safety, feasibility and preliminary outcomes of umbilical cord Wharton's jelly-derived MSCs for new-onset type I diabetics [35]. The MSC-treated group underwent two intravenous infusions (mean cell count of $2.6 \times 10^{7}$ ) separated 4 weeks apart. Postprandial glucose and $\mathrm{HbA} 1 \mathrm{c}$ measurements were lower in the experimental cohort between 9 and 24 months after MSC infusion. Also, insulin usage and fasting C-peptide were significantly improved in the MSC group. The study authors concluded that in their small study, not powered to detect functional differences, the transplant of umbilical cord MSCs is feasible and safe. A pilot study in China involving delivering placenta-derived MSCs to patients with long-standing DM type 2 revealed the transplantation was safe, easy and potentially efficacious [36]. This investigation included ten patients with type 2 diabetes for a duration $\geq 3$ years, insulin dependent ( $\geq 0.7 \mathrm{U} / \mathrm{kg} /$ day) for at least 1 year and poorly controlled glucose. The subjects received on average $1.35 \times 10^{6} / \mathrm{kg}$ placental stem cells on three separate occasions with 1-month intervals between intravenous infusions. Six months after treatment, the insulin dosage and $\mathrm{HbA1C}$ measurements for all the patients improved. Moreover, C-peptide and insulin release were also higher after MSC treatment. In addition, this study included a group of individuals that translate closer to actual clinical scenarios, as they also had other comorbidities, including heart disease, kidney disease and vascular complications. Lately, researchers have de- 


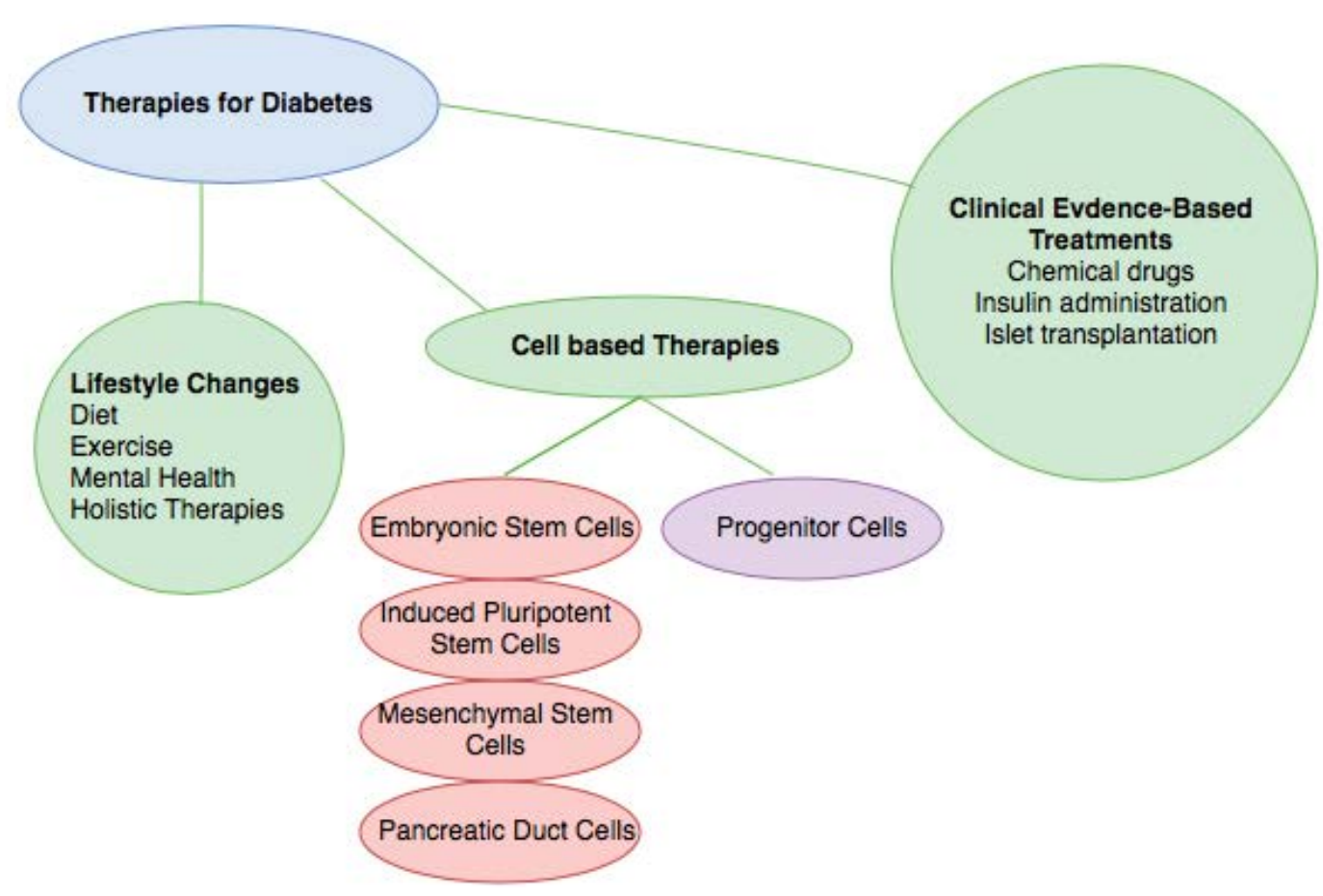

Figure 3: Current therapies for Diabetes Mellitus.

veloped insulin-secreting MSCs and delivered them, in combination with hematopoietic stem cells, to patients with DM type I [37].

\section{Conclusion}

Both DM type 1 and type 2 are among the most amenable diseases for treatment. Functional restoration of existing beta-cells, transplantation of stem cells or stem cell-derived beta-like cells might provide new opportunities for treatment (Figure 3). However, the use of stem cells to generate a renewable source of beta-cells for diabetes treatment remains challenging, largely due to safety concerns. There has been a large number of small published studies that indeed do not constitute a solid scientific proof of the efficacy of different stem cells being tried. The introduction of pre-prepared or frozen cells, like the MSC of umbilical or bone marrow origin, by different pharmaceutical companies has proven extremely expensive at this point and definitely out of reach to the vast majority of individuals. Larger studies are needed to advance the field and understand the best way to realise its potential. We believe stem cell therapy should only be used within clinical trials at this time, until enough evaluable data becomes available. The laboratory methods, like culture conditions and methods of cell numbering, have to be better thought of and more uniformly standardized, and the interpretation of the results should be done critically. In summary, regenerative medicine remains a new and exciting field of research that holds much promise into the treatment of patients with endocronologic diseases of all ages. Evidence based clinical treatment of diabetic symptoms only adds to the disease burden. With the advent of stem cell therapy, the potential to eradicate diabetes seems to be on the horizon.

\section{References}

1. Mathers CD, Loncar D (2006) Projections of global mortality and burden of disease from 2002 to 2030. PLoS Med 3: e442.

2. William L Isley, Mark E Molitch (2005) Type 1 Diabetes. The Journal of Clinical Endocrinology \& Metabolism 90: E2.

3. Makam AN, Nguyen OK (2017) An evidence-based medicine approach to antihyperglycemic therapy in diabetes mellitus to overcome overtreatment. Circulation 135: 180-195.

4. Mirmira RG (2017) Reprogramming Beta cells in Diabetes: Step closer to cure. MedScape: Diabetes and Endocrinology.

5. Li J, Casteels T, Frogne T, Ingvorsen C, Honoré C, et al. (2017) Artemisinins target GABA $_{A}$ receptor signaling and impair $\alpha$ cell identity. Cell 168: 86.e15-100.e15.

6. Wang P, Alvarez-Perez JC, Felsenfeld DP, Liu H, Sivendran $S$, et al. (2015) A high-throughput chemical screen reveals that harmine-mediated inhibition of DYRK1A increases human pancreatic beta cell replication. Nat Med 21: 383-388.

7. Fadini GP, Sartore S, Agostini C, Avogaro A (2007) Significance of endothelial progenitor cells in subjects with diabetes. Diabetes Care 30: 1305-1313.

8. Zeng YC, Ricordi C, Lendoire J, Carroll PB, Alejandro R, et al. (1993) The effect of prednisone on pancreatic islet autografts in dogs. Surgery 113: 98-102.

9. Lakey JR, Warnock GL, Rajotte RV, Suarez-Alamazor ME, Ao Z, et al. (1996) Variables in organ donors that affect the recovery of human islets of Langerhans. Transplantation 61: 1047-1053.

10. Woodfield J (2017) Success for new method of islet cell transplantation in type 1 diabetes. Diabetes News.

11. Ryan EA, Lakey JR, Rajotte RV, Korbutt GS, Kin T, et al. (2001) Clinical outcomes and insulin secretion after islet transplantation with the Edmonton protocol. Diabetes 50: 710-719.

12. Shapiro AM, Lakey JR, Ryan EA, Korbutt GS, Toth E, et al. (2000) Islet transplantation in seven patients with type 1 diabetes mellitus using a glucocorticoid-free immunosuppressive regimen. N Engl J Med 343: 230-238. 
13. Shapiro AM, Ricordi C, Hering BJ, Auchincloss H, Lindblad $\mathrm{R}$, et al. (2006) International trial of the Edmonton Protocol for islet transplantation. N Engl J Med 355: 1318-1330.

14. Westenfelder C, Gooch A, Hu Z, Ahlstrom J, Zhang P (2017) Durable control of autoimmune diabetes in mice achieved by intraperitoneal transplantation of "Neo-Islets," three-dimensional aggregates of allogeneic islet and "mesenchymal stem cells". Stem Cells Transl Med 6: 16311643.

15. Barton FB, Rickels MR, Alejandro R, Hering BJ, Wease $S$, et al. (2012) Improvement in outcomes of clinical islet transplantation: 1999-2010. Diabetes Care 35: 1436-1445.

16. Carlow DA, Gold MR, Ziltener HJ (2009) Lymphocytes in the peritoneum home to the omentum and are activated by resident dendritic cells. J Immunol 183: 1155-1165.

17. Litbarg NO, Gudehithlu KP, Sethupathi P, Arruda JA, Dunea $\mathrm{G}$, et al. (2007) Activated omentum becomes rich in factors that promote healing and tissue regeneration. Cell Tissue Res 328: 487-497.

18. Wehbe T, Chahine NA, Sissi S, Isabelle Abou-Joaude, Louis Chalhoub (2016) Bone marrow derived stem cell therapy for type 2 diabetes mellitus. Stem Cell Investig 3: 87.

19. Bhansali A, Asokumar P, Walia R, Bhansali S, Gupta V, et al. (2014) Efficacy and safety of autologous bone marrowderived stem cell transplantation in patients with type 2 diabetes mellitus: A randomized placebo-controlled study. Cell Transplant 23: 1075-1085.

20. Wu Z, Cai J, Chen J, Huang L, Wu W, et al. (2014) Autologous bone marrow mononuclear cell infusion and hyperbaric oxygen therapy in type 2 diabetes mellitus: An open-label, randomized controlled clinical trial. Cytotherapy 16: 258-265.

21. Subrammaniyan $R$, Amalorpavanathan J, Shankar R, Rajkumar M, Baskar S, et al. (2011) Application of autologous bone marrow mononuclear cells in six patients with advanced chronic critical limb ischemia as a result of diabetes: Our experience. Cytotherapy 13: 993-999.

22. Wang L, Zhao S, Mao H, Zhou L, Wang ZJ, et al. (2011) Autologous bone marrow stem cell transplantation for the treatment of type 2 diabetes mellitus. Chin Med J (Engl) 124: 3622-3628.

23. Kodama S, Faustman DL (2004) Routes to regenerating islet cells: Stem cells and other biological therapies for type 1 diabetes. Pediatr Diabetes 5: 38-44.

24. Odorico JS, Kaufman DS, Thomson JA (2001) Multilineage differentiation from human embryonic stem cell lines. Stem Cells 19: 193-204.
25. Calafiore R, Montanucci P, Basta G (2014) Stem cells for pancreatic $\beta$-cell replacement in diabetes mellitus: Actual perspectives. Curr Opin Organ Transplant 19: 162-168.

26. Grompe M (2002) Adult versus embryonic stem cells: It's still a tie. Mol Ther 6: 303-305.

27. Thomson JA, Itskovitz-Eldor J, Shapiro SS, Waknitz MA, Swiergiel JJ, et al. (1998) Embryonic stem cell lines derived from human blastocysts. Science 282: 1145-1147.

28. Shamblott MJ, Axelman J, Wang S, Bugg EM, Littlefield JW, et al. (1998) Derivation of pluripotent stem cells from cultured human primordial germ cells. Proc Natl Acad Sci U S A 95: 13726-13731.

29. Takahashi K, Yamanaka S (2006) Induction of pluripotent stem cells from mouse embryonic and adult fibroblast cultures by defined factors. Cell 126: 663-676.

30. Tachibana M, Amato P, Sparman M, Nuria Marti Gutierrez, Rebecca Tippner-Hedges, et al. (2013) Human embryonic stem cells derived by somatic cell nuclear transfer. Cell 153: 1228-1238.

31. Jiang J, Au M, Lu K, Eshpeter A, Korbutt G, et al. (2007) Generation of insulin-producing islet-like clusters from human embryonic stem cells. Stem Cells 25: 1940-1953.

32. Schulz TC, Young HY, Agulnick AD, Babin MJ, Baetge EE, et al. (2012) A scalable system for production of functional pancreatic progenitors from human embryonic stem cells. PLoS One 7: e37004.

33. Bruin JE, Erener S, Vela J, Hu X, Johnson JD, et al. (2014) Characterization of polyhormonal insulin-producing cells derived in vitro from human embryonic stem cells. Stem Cell Res 12: 194-208.

34. Kirk K, Hao E, Lahmy R, Itkin-Ansari P (2014) Human embryonic stem cell derived islet progenitors mature inside an encapsulation device without evidence of increased biomass or cell escape. Stem Cell Res 12: 807-814.

35. Hu J, Yu X, Wang Z, Wang F, Wang L, et al. (2013) Long term effects of the implantation of Wharton's jelly-derived mesenchymal stem cells from the umbilical cord for newlyonset type 1 diabetes mellitus. Endocr J 60: 347-357.

36. Jiang R, Han Z, Zhuo G, Qu X, Li X, et al. (2011) Transplantation of placenta-derived mesenchymal stem cells in type 2 diabetes: A pilot study. Front Med 5: 94-100.

37. Vanikar AV, Dave SD, Thakkar UG, Trivedi HL (2010) Cotransplantation of adipose tissue-derived insulin-secreting mesenchymal stem cells and hematopoietic stem cells: A novel therapy for insulin-dependent diabetes mellitus. Stem Cells Int 2010: 1-5. 